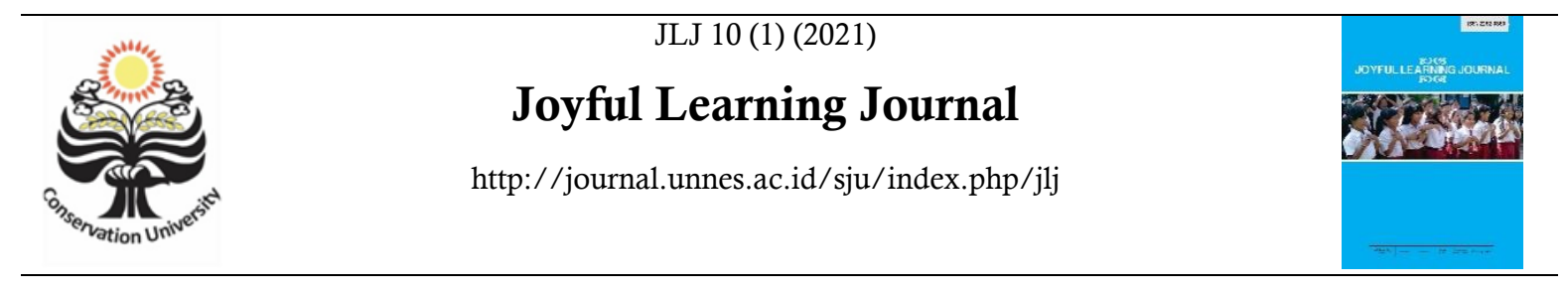

\title{
PELESTARIAN BUDAYA INDONESIA MELALUI INDONESIAN CULTURAL WEEK
}

\section{Nifo Ria Nurendra Pangestika ${ }^{\bowtie}$, Atip Nurharini}

Jurusan Pendidikan Guru Sekolah Dasar, Fakultas Ilmu Pendidikan, Universitas Negeri Semarang, Indonesia

\section{Info Artikel}

Sejarah Artikel:

Diterima Jan 2021

Disetujui Feb 2021

Dipublikasikan Mar

2021

Keywords: preservation of Indonesian cultural, IndonesianCultural Week

\begin{abstract}
Abstrak
Banyaknya budaya yang ada di Indonesia sangat perlu untuk dilestarikan, terutama di Elementary School of Semarang Multinational School yang mayoritas siswanya merupakan warga negara asing, maka sekolah ini mengadakan kegiatan Indonesian Cultural Week guna melestarikan budaya Indonesia. Penelitian ini bertujuan mendeskripsikan pelestarian budaya Indonesia melalui kegiatan Indonesian Cultural Week yang dilaksanakan di Elementary School of Semarang Multinational School. Penelitian ini menggunakan pendekatan kualitatif. Penelitian dilaksanakan di Elementary School of Semarang Multinational School. Sampel dalam penelitian ini adalah kepala sekolah, guru, dan siswa yang berjumlah 13 orang yang ditentukan dengan teknik purposive sampling. Teknik pengumpulan data menggunakan observasi, wawancara, dokumentasi dan catatan lapangan. Analisis data dilakukan melalui tahap reduksi data, penyajian data, dan penarikan kesimpulan. Hasil penelitian menunjukkan bahwa pelestarian budaya lokal di Elementary School of Semarang Multinational School dilaksanakan dengan sangat baik melalui kegiatan Indonesian Cultural Week dengan dukungan dari seluruh pihak terkait yaitu kepala sekolah, guru, staff, siswa, dan juga orang tua yang ditunjukkan dengan adanya penambahan tingkat pengetahuan siswa mengenai budaya Indonesia.Simpulan dari penelitian ini adalah kegiatan Indonesian Cultural Week dapat melestarikan kebudayaan lokal di Elementary School of Semarang Multinaional School termasuk dalam kategori baik. Pelaksanaan kegiatan Indonesian Cultural Week meliputi upaya mempertahankan budaya lokal, pelestarian budaya didasarkan pada kebutuhan, serta terdapat strategi pelestarian budaya. Faktor pendukung pelaksanaan kegiatan Indonesian Cultural Week yaitu dimulai dari tahap persiapan yang meliputi penyusunan rancangan kegiatan, anggaran dana, tempat dan waktu pelaksanaan dan penyusunan kepanitiaan, sampai dengan tahap pelaksanaan kegiatan dan evaluasi pasca kegiatan
\end{abstract}

\begin{abstract}
Many cultures in Indonesia are very necessary to be preserved, especially in Elementary School of Semarang Multinational School, where the majority of students are foreign nationals, so this school holds Indonesian Cultural Week activities to preserve Indonesian culture. This research aims to describe the preservation of Indonesian culture through Indonesian Cultural Week activities held at Elemenary School of Semarang Multinational School. This research uses qualitative approach. The research was conducted at Elementary School of Semarang Multinational School. The samples in this study were principals, teachers, and students of 13 people determined by purposive sampling techniques. Data collection techniques using observation, interviews, documentation and field notes. Data analysis is done through data reduction, data presentation, and conclusion drawing. The results showed that the preservation of local culture at Elementary School of Semarang Multinational School was carried out very well through Indonesian Cultural Week activities with support from all relevant parties, namely principals, teachers, staff, students, and also parents, which was shown by the addition of students' level of knowledge about Indonesian culture. The conclusion of this research is that Indonesian Cultural Week activities can preserve local culture at Elementary School of Semarang Multinaional School in the good category. The implementation of Indonesian Cultural Week activities includes efforts to maintain local culture, cultural preservation based on needs, and there are strategies for cultural preservation. Supporting factors for the implementation of Indonesian Cultural Week activities are starting from the preparation stage which includes the preparation of the draft activities, budget funds, place and time of implementation and preparation of committee, up to the stage of implementation of activities and post-activity evaluation
\end{abstract}

(C) 2021 Universitas Negeri Semarang

\footnotetext{
Alamat korespondensi:

Wonosari, Gunungkidul, D.I.Yogyakarta

E-mail: niforianp23@gmail.com
} 


\section{PENDAHULUAN}

Kebudayaan merupakan sesuatu yang bersifat superorganic, karena kebudayaan bersifat turun temurun dari generasi ke generasi berikutnya, walaupun manusia yang ada didalam masyarakat senantiasa silih berganti disebabkan kematian dan kelahiran (Melville J.Herkovits dalam Soerjono soekamto: 2006: 150). Kebudayaan merupakan tradisi yang diikuti oleh kominitas tertentu. Berasal dari nenek moyang terdahulu yang sampai saat ini masih diyakini dan diterima oleh seluruh masyarakat didunia sebagai sebuah warisan yang luhur. Seluruh negara di dunia memiliki budaya yang beragam sebagai identitasnya. Budaya di suatu negara tentu akan berbeda dengan budaya di negara lain. Adanya ragam budaya di berbagai negara tidak hanya merupakan aset bergarga, namun juga sebagai simbol kehidupan yang ada di dalam negara tersebut.

Indonesia merupakan negara kaya yang memiliki ragam budaya. Indonesia yang merupakan negara dengan beragam ras, suku, agama, bangsa tentu akan menciptakan budaya yang beragam pula. Undang-undang Dasar 1945 Pasal 32 menegaskan bahwa: "Negara memajukan kebudayaan nasional Indonesia serta penjelasannya antara lain menyatakan usaha kebudayaan harus menuju kearah kemajuan adab, budaya dan persatuan dengan tidak menolak bahan-bahan baru dari kebudayaan asing yang dapat memperkembangkan atau memperkaya kebudayaan bangsa sendiri, serta mempertinggi derajat kemanusiaan bangsa Indonesia." Dari pasal tersebut, seluruh warga Indonesia wajib melestarikan budaya Indonesia dengan berbagai upaya. Adanya budaya asing yang masuk ke Indonesia tidak selamanya merupakan suatu hal yang negatif, namun juga memiliki nilai positif jika budaya asing tersebut diseleksi dengan benar dan tidak melanggar etika dan budaya yang melekat di Indonesia. Budaya asing yang dinilai positif dan sesuai dengan karakter kebudayaan bangsa Indonesia dapat memperkaya budaya Indonesia.

Pelestarian adalah sebuah upaya yang berdasar, dan dasar ini disebut juga faktorfaktor yang mendukungnya baik itu dari dalam maupun dari luar dari hal yang dilestarikan. Maka dari itu, sebuah proses atau tindakan pelestarian mengenal strategi atapun teknik yang didasarkan pada kebutuhan dan kondisinya masing-masing ( Chaedar, 2006: 18). Kelestarian tidak mungkin berdiri sendiri, oleh karena senantiasa berpasangan dengan perkembangan, dalam hal ini kelangsungan hidup. Kelestarian merupakan aspek stabilisasi kehidupan manusia, sedangkan kelangsungan hidup merupakan percerminan dinamika. (Soekanto, 2003: 432)

Didukung penelitian oleh Ashar Pratama (2014) dengan judul "Upaya Pelestarian Budaya Lokal oleh Pusat Kegiatan Belajar Mengajar (PKBM) Dewi Fortuna melalui Pelatihan Pengkaderan Berbasis Budaya". Hasil penelitian menunjukkan bahwa generasi muda di Desa Danguran menunjukkan respon positif dan negatif terhadap pelatihan pengkaderan yang dilakukan oleh PKBM Dewi Fortuna yang meliputi pelatihan pedalangan, tari, sindhen, karawitan dan tatah sungging dengan metode ceramah dan praktek dimana evaluasi kegiatan dilakukan dengan praktek melalui pentas seni budaya.

Penelitian yang dilakukan oleh Ibnu Fatkhu Royana (2017) yang berjudul "Pelestarian Kebudayaan Nasional melakui Permainan Tradisional dalam Pendidikan Jasmani". Hasil penelitian ini menunjukkan bahwa pengaruh berkembangnya teknologi dan mesia sosial mengubah permainan anakanak dimasa sekarang yang sebelumnya berkelompok dan aktif menjadi individual dan pasif. Penelitian ini menguraikan bagaimana melestarikan budaya nasional berupa permainan tradisional untuk menggeser ketergantungan anak terhadap gadget melalui pendidikan asmani.

Penelitian dilakukan oleh Ana Irhandayaningsih pada tahun 2018 dengan judul "Pelestarian Kesenian Tradisional sebagai Upaya dalam Menumbuhkan Kecintaan Budaya Lokal di Masyarakat Jurang Blimbing Tembalang". Memaparkan tentang berbagai permasalahan terkait dengan pelestarian kesenian tradisional di masyarakat Jurang Blimbing Tembalang, yang mengkaji tentang seni sebagai identitas lokal, dokumentasi sebagai wadah pelestarian, rancangan pelestarian kesenian melalui kemasan multimedia, proses implementasi rancangan pelestarian, serta budaya lokal.

Penelitian yang dilakukan oleh Gustiana Mega Anggita dkk pada tahun 2018 yang berjudul "Eksistensi Permainan Tradisional Sebagai Warisan Budaya 
Bangsa". Penelitian ini dilakukan untuk mengetahui keberadaan, jumlah dan jenis permainan tradisional yang ada si Kabupaten Semarang. Hasil dari penelitian ini menunjukkan ada sepuluh permainan tradisional di Kabupaten Semarang yang terdiri atas bentengan, gobak sodor, sunda manda, bakiak, bintang bergilir, bola bakar, egrang, rok dodok, kucing tikus dan ular naga.

Penelitian yang dilakukan oleh $\mathrm{M}$. Hasan Al Ambari (2018) yang berjudul "Pengaruh Permainan Tradisional Terhadap Perkembangan Anak di Kampung Dolanan. Penelitian ini dilakukan karena semakin berkembang permainan modern dan pengaruh permainan tradisional terhadap perkembangan anak. Hasil penelitian ini adalah adanya pengaruh positif permainan tradisional terhadap perkembangan anak yaitu pengaruh secara kognitif, emosi, fisik, psikososial anak. Dimana pengaruh tersebut dihasilkan oleh permainan tradisional yang memiliki nilai-nilai educative dan berbeda dengan permainan modern yang diyakini memiliki efek-efek negatif bagi perkembangan anak.

Penelitian yang dilakukan oleh Murdiono Jarkasih (2017) dengan judul "Pengaruh Budaya Jawa Terhadap Pola Perilaku Masyarakat Desa Margolembo Kecamatan Mangkutana Kabupaten Luwu Timur". Hasil penelitian ini menunjukkan etnis Jawa mempengarhi etnis non Jawa dilihat dari setiap acara-acara yang dilakukan oleh etnis Jawa yang berhubungan dengan kebudayaan Jawa, seperti slametan, bersih desa, dan acara turun sawah mereka non Jawa selalu mengikutinya dan mudah berbaur, bahkan mereka biasa melakukan kebudayaan Jawa tersebut.

\section{METODE PENELITIAN}

Penelitian ini menggunakan pendekatan kualitatif. Pendekatan kualitatif digunakan untuk meneliti kondisi objek yang alamiah, dimana peneliti sebagai instrumen kunci dan hasilnya menekankan makna daripada generalisasi (Sugiyono, 2016: 15). Penelitian kualitatif merupakan penelitian yang bermaksud untuk memahami fenomena tentang apa yang dialamioleh subjek penelitian misalnya perilaku, persepsi, motivasi, dan tindakan secaraholistik dengan cara deskripsi dalam bentuk kata-kata (Moleong, 2012:6).
Penggunaan pendekatan kualitatif karena analisis data dilakukakan dengan mereduksi data dari teknik lain dengan keabsahan data menggunakan triangulasi. Peneliti tidak melakukan manipulasi terhadap semua kegiatan, keadaan, dan kejadian selama proses penelitian berlangsung. Metode deskriptif dipilih karena penelitian ini bertujuan untuk mendeskripsikan pelestarian budaya lokal Indonesia melalui kegiatan Indonesian Cultural Week di Semarang Multinational School.

Selama proses penelitian, peneliti mengumpulkan data melalui berbagai macam teknik, yang kemudian direduksi untuk disajikan dalam bentuk uraian kata-kata yang bertujuan untuk mendekripsikan tentang pelestarian budaya lokal, aktivitas siswa dalam pelaksanaan Indonesian Cultural Week, dan faktor-faktor pendukung pelaksanaan Indonesian Cultural Week.

\section{HASIL DAN PEMBAHASAN}

Hasil dan pembahasan meliputi pelestarian budaya lokal di Semarang Multinational Scool melalui kegiatan Indonesian Cultural Week.

Pelaksanaan kegiatan Indonesian Cultural Week dapat melestarikan kebudayaan lokal di SD Semarang Multinaional School dibuktikan dengan adanya kegiatan kebudayaan yang dilakukan oleh seluruh siswa SD Semarang Multinational School dengan didampingi oleh guru. Kegiatan kebudayaan yang dilaksanakan tentu beragam sesuai dengan tingkatan kelas masing-masing. Kelas 1: mewarnai bendera merah putih, membuat boneka dari benang wol yang ditempelkan di kertas karton, menyanyikan dan menarikan lagu daerah Jawa Tengah yaitu Cublakcublak Suweng. Kelas 2: mengenal baju adat daerah yang ada di Indonesia, membuat hiasan dinding yang bertajub merah putih, berlatih fashion show menggunakan baju adat dan juga atribut daerah Indonesia. Kelas 3: mewarnai wayang, bermain paku botol, bermain dakon, gerak dan lagu Yamko Rambe Yamko, mempelajari makanan khas daerah Indonesia. Kelas 4: mewarnai wayang, membuat boneka dari kain flanel dan kain batik, bermain petak umpet dan sundamanda. Kelas 5 dan 6: mewarnai wayang, drama dengan lagu "Naik Delman"

Faktor Pendukung dalam Pelaksanaan Indonesian Cultural Week dinilai dengan tiga 
indikator yaitu: 1) perencanaan, 2) pelaksanaan dan pengorganisasian, 3) pengendalian dimana masing masing indicator memiliki descriptor. Dalam indikator perencanaan, ada 4 deskriptor yaitu terdapat strategi perencanaan pelaksanaan Indonesian Cultural Week, terdapat sumber daya yang mendukung pelaksanaan Indonesian Cultural Week, terdapat lingkungan yang mendukung pelaksanaan Indonesian Cultural Week, terdapat tujuan pelaksanaan Indonesian Cultural Week yang jelas. Dalam indikator pelaksanaan dan pengorganisasian terdapat 3 deskriptor yaitu terdapat pengalokasian sumber daya dalam pelaksanaan Indonesian Cultural Week, penyusunan jadwal kerja yang baik, dan adanya koordinasi antar unit dalam suatu kepanitiaan. Sedangkan dalam indicator pengendalian terdapat 3 deskriptor yaitu terdapat evaluasi pelaksanaan Indonesian Cultural Week, adanya kontrol resiko dalam pelaksanaan Indonesian Cultural Week, terdapat gladi bersih sebagai persiapan terakhir pementasan.

Pelaksanaan kegiatan Indonesian Cultural Week dapat melestarikan kebudayaan lokal di SD Semarang Multinational School dinilai dari 3 indikator pengamatan meliputi: 1) mempertahankan budaya lokal; 2) pelestarian budaya didasarkan pada kebutuhan; 3) terdapat strategi pelestarian budaya dimana setiap indicator udah terlaksana dengan baik. Guru memperkenalkan budaya lokal Indonesia kepada siswa dengan cara menjelaskan berbagai macam budaya lokal Indonesia seperti wayang, tari daerah, permainan tradisional, lagu daerah, kesenian lokal, dan lain-lain. Selain itu, guru juga menunjukkan beberapa gambar menarik tentang budaya lokal Indonesia. Siswa terlihat bersemangat dan sangat tertarik untuk memperhatikan penjelasan guru. Budaya yang dikenalkan kepada siswa disesuaikan dengan tingkat pemahaman siswa. Kepala sekolah dan guru membentuk rangkaian kegiatan yang berbeda-beda disetiap kelas. Kegiatan disortir dan diurutkan sesuai dengan tingkat kesulitan pelaksanaannya. Semakin tinggi kelasnya maka semakin tinggi pula tingkat kesulitan pelaksanaan rangkaian kegiatan dalam pelaksanaan Indonesian Cultural Week. guru menggunakan strategi pengenalan budaya. Sebelum menyampaikan materi tentang budaya kepada siswa, guru membangkitkan rasa ingin tahu dan penasaran siswa sehingga siswa sangat antusias dalam mendengarkan penjelasan guru.

Faktor pendukung dalam pelaksanaan indonesian Cultural Week dinilai dengan tiga indikator yaitu: 1) perencanaan, 2) pelaksanaan dan pengorganisasian, 3) pengendalian. terdapat strategi perencanaan pelaksanaan Indonesian Cultural Week. Hasil wawancara peneliti kepada kepala sekolah tentang perencanaan pelaksanaan Indonesian Cultural Week menunjukkan bahwa persiapan pelaksanaan Indonesian Cultural Week dimulai sejak Bulan Maret dengan tujuan semua dapat terplanning dengan baik dan diharapkan pelaksanaan Indonesian Cultural Week bisa maksimal. Sumber daya yang ada baik sumber daya manusia, financial, dan material dialokasikan secara maksimal dalam pelaksanaan Indonesian Cultural Week. Setiap dana dianggarkan sesuai kebutuhan dan dicatat oleh bendahara event. Untuk sumber daya manusia sudah diploting dalam kepanitiaan. Penyusunan jadwal kerja dalam pelaksanaan Indonesian Cultural Week disusun dengan baik. Terdapat evaluasi pelaksanaan Indonesian Cultural Week yang terlihat saat proses pelaksanaan Indonesian Cultural Week telah selesai. Seluruh panitia pelaksanaan menggelar rapat untuk mengevaluasi proses pelaksanaan Indonesian Cultural Week.

\section{SIMPULAN}

Berdasarkan hasil penelitian dan pembahasan dari rumusan masalah yang telah diurakan tersebut, maka peneliti dapat memberikan kesimpulan sebagai berikut.

Pelaksanaan kegiatan Indonesian Cultural Week dapat melestarikan kebudayaan lokal di Elementary School of Semarang Multinaional School termasuk dalam kategori baik. Pelaksanaan kegiatan Indonesian Cultural Week meliputi upaya mempertahankan budaya lokal, pelestarian budaya didasarkan pada kebutuhan, terdapat strategi pelestarian budaya, pelestarian mengikuti perkembangan zaman.

Faktor pendukung pelaksanaan kegiatan Indonesian Cultural Week yaitu dimulai dari tahap persiapan yang meliputi penyusunan rancangan kegiatan, anggaran dana, tempat dan waktu pelaksanaan dan penyusunan kepanitiaan, sampai dengan tahap pelaksanaan kegiatan dan evaluasi pasca kegiatan. 


\section{DAFTAR PUSTAKA}

Cariaga, Jane N. 2014. Documention And Notation Of The Traditional Dances Of The Yogads Of Isabela. Journal Of Art, Sciene \& Commerce (EISSN2229-4686.ISSN2231-4172). Vol 5 (4): 71-82. October 2014.

Khutniah, Nailul dan Veronica Eri, I. 2012. Upaya Mempertahankan Eksistensi Tari Kridajati Di Sanggar Hayu Budaya Kelurahan Pengkol Jepara. Dalam Jurnal Seni Tari. Vol 1 No. 1. Hal. 9-21

Koentjaraningrat. 1994. Kebudayaan Jawa. Jakarta: Balai Pustaka.

Sardi. 2010. Persepsi dan Partisipasi Generasi Muda Terhadap Pelestarian Kebudayaan Dan Kesenian Tradisional Kuda Lumping. Jurnal Ilmiah Pendidikan Sejarah IKIP Veteran Semarang. Hal 50-59

Sensai, Peerapong, et al. 2014. The Dynamism of Traditional Dance in Mukdahan Province. Asian Culture and History (ISSN 1916-9655 EISSN 19169663). Vol. 6 (2): 106-117. June 12, 2014.

Sugiyono. 2008. Metode Penelitian Pendidikan: Pendekatan Kuantitatif, Kualitatif, dan $R \& D$. Bandung: Alfabeta.

Abdullah, Iqbal Alan. 2009. Manajemen Konferensi dan Event. Yogyakarta: Gadjah Mada University Press

Susilantini, Endah. 2002. Kehidupan Penari Lengger Di Desa Giyanti Kecamatan Selomerto Kabupaten Wonosobo. Patra Widya. Vol 3 No. 2.
Hartono, Juni, Budaya Jawa (Kepercayaan, Kekerabatan, Sistem Politik,Ekonomi, dan Kesenian Budaya Jawa), http://www.guruips.com/2016/11/bu dayajawa-kepercayaankekerabatan.html 3 Januari 2017

Jazuli, M.2005. Mandala Pendidikan Seni (The Mandala of Art Education).Jurnal Harmonia VI (3)

Kasiyan.2002.Pendidikan Kesenian dalam Pembangunan Karakter Bangsa.Jurnal Cakrawala Pendidikan.XXI(1):2

Kamtini, dan Husni Wardi Tanjung. 2006. Berkreativitas melalui Kerajianan Tangan dan Kesenian di Sekolah Dasar. Jakarta:Depdiknas

Hawkins. Alma M. (1990). Mencipta Lewat Tari. Yogyakarta: ISI Yogyakarta Gede Pitana, Bali Post, edisi Minggu 21 Desember 2003

Kamil, M. (2010). Model Pendidikan dan Pelatihan. Bandung: Alfabeta

Lexy J. Moleong. (2004). Metodologi Penelitian Kualitatif. Bandung: Remaja Rosdakarya

Sri Mulyono. (1982). Wayang: Asal-Usul, Filsafat, dan Masa Depannya. Jakarta: Gunung Agung

Suharsimi Arikunto. (2010). Manajemen Penelitian. Jakarta: Bumi Aksara

Sumjati. (2001). Manusia dan Dinamika Budaya dari Kekerasan Sampai Baratayuda. Yogyakarta: Bigraf

Peursen, Van C.A. (1988). Strategi Kebudayaan. Jakarta: Kanisius

Warsito, Antropogi Budaya, Yogyakarta: Ombak, 2012. 